\title{
Keratinocyte growth factor accelerates compensatory growth in the remaining lung after trilobectomy in rats
}

\author{
Keitaro Matsumoto, MD, ${ }^{\text {a,b }}$ Takeshi Nagayasu, MD, ${ }^{\text {a }}$ Yoshitaka Hishikawa, MD, ${ }^{\mathrm{b}}$ Tsutomu Tagawa, MD, ${ }^{\mathrm{a}}$ \\ Takatomo Yamayoshi, MD, ${ }^{\mathrm{a}}$ Takafumi Abo, MD, ${ }^{\mathrm{a}}$ Shuichi Tobinaga, MD, ${ }^{\mathrm{a}}$ Katsuro Furukawa, MD, ${ }^{\mathrm{a}}$ and Takehiko Koji, PhD ${ }^{\mathrm{b}}$
}

\begin{abstract}
Objective: In rats pulmonary resection is followed by lung compensatory growth. However, the molecular mechanism underlying lung compensatory growth remains unclear. Keratinocyte growth factor is expressed in lung tissue and is considered a possible mitogen for lung epithelial cells. The objectives of this study were to define the role of keratinocyte growth factor and its receptor in rat lung compensatory growth after trilobectomy and the effect of exogenous keratinocyte growth factor gene transfection.
\end{abstract}

\begin{abstract}
Methods: Adult Lewis rats were used. Right trilobectomy was performed in the operation group and sham thoracotomy in the sham group. In the operation group, keratinocyte growth factor-FLAG or FLAG expression vector was transfected directly into the lung by means of electroporation. Expression of keratinocyte growth factor and its receptor and alveolar cell proliferation index based on proliferating cell nuclear antigen levels were measured in the right lung at day 14 after the operation.

Results: Proliferating cell nuclear antigen, keratinocyte growth factor, and keratinocyte growth factor receptor expression in lung epithelial cells was significantly increased at day 4 after trilobectomy. Transfection of keratinocyte growth factor-FLAG expression vector resulted in further significant enhancement of proliferating cell nuclear antigen at day 4 after trilobectomy; however, the transfection of FLAG expression vector did not alter the enhancement of proliferating cell nuclear antigen. Exogenous expression of keratinocyte growth factor in the remaining lung by means of electroporation significantly augmented epithelial proliferation and decreased the average airspace distance (mean linear intercept).
\end{abstract}

Conclusion: Our results implicate keratinocyte growth factor in the induction of alveolar epithelial cell proliferation for compensatory lung growth and indicate that overexpression of keratinocyte growth factor in the remaining lung by means of electroporation significantly augmented lung epithelial proliferation.

The lung undergoes compensatory growth after lung injury or surgical resection. The growth process involves increasing lung volume, weight, cell proliferation, and pulmonary function, ${ }^{1,2}$ but the mechanism responsible for this process is unclear. Understanding lung compensatory growth requires clarification of the molecular mechanism underlying the induction of lung epithelial cell proliferation.

Rubin and colleagues ${ }^{3}$ discovered keratinocyte growth factor (KGF) as a mesenchymal cell-derived epithelial cell mitogen, and subsequently the KGF receptor (KGFR; bek IIIb) was identified in various epithelial cells. KGF expression is upregulated in rodent models of lung injury and has been implicated in the induction of alveolar epithelial cell proliferation. ${ }^{4}$ Kaza and associates ${ }^{5}$ demonstrated that exogenous KGF enhanced postpneumonectomy compensatory lung growth through alveolar proliferation. The findings

\footnotetext{
From the Division of Surgical Oncology, Department of Translational Medical Sciences, ${ }^{\mathrm{a}}$ and the Department of Histology and Cell Biology, ${ }^{\mathrm{b}}$ Nagasaki University Graduate School of Biomedical Sciences, Nagasaki, Japan.

Received for publication March 2, 2008; revisions received Oct 27, 2008; accepted for publication Nov 22, 2008.

Address for reprints: Takehiko Koji, PhD, Department of Histology and Cell Biology, Nagasaki University Graduate School of Biomedical Sciences, Sakamoto 1-12-4, Nagasaki 852-8523, Japan (E-mail: tkoji@nagasaki-u.ac.jp).

J Thorac Cardiovasc Surg 2009;137:1499-507

$0022-5223 / \$ 36.00$

Copyright (c) 2009 by The American Association for Thoracic Surgery

doi:10.1016/j.jtcvs.2008.11.037
}

of that study were significant for investigating the role of exogenous KGF on lung compensatory growth. However, it is still unclear whether endogenous KGF and KGFR play a direct role in the induction of lung epithelial proliferation and differentiation during the compensatory growth of the lung after lobectomy.

We hypothesized that KGF and KGFR are involved in compensatory lung growth and that exogenous KGF administration accelerates the compensatory lung growth. In the present study we investigated first the temporal and spatial relationships between the proliferation of lung epithelial cells and the expression of $\mathrm{KGF} / \mathrm{KGFR}$ in regenerating rat lung after trilobectomy by using immunohistochemistry. In the second part of the study, KGF was expressed in the remaining lung tissue to examine the effect of prolonged exposure to KGF on lung growth in vivo. For prolonged in situ expression of KGF in the lung, we used electroporation in this study because, unlike other methods, it facilitates the introduction of foreign genes into a specific area of the desired tissue with minimal damage ${ }^{6}$ and few side effects.

\section{MATERIALS AND METHODS}

\section{Animals, Surgical Procedure, and Tissue Preparation}

Pathogen-free 8-week-old male Lewis rats weighing 220 to $270 \mathrm{~g}$ used as adult rats were purchased from Charles River Japan (Kanagawa, Japan). Each rat was anesthetized with intraperitoneal injection of $25 \mathrm{mg} / \mathrm{kg}$ sodium pentobarbital. The right lung of rats consists of 4 lobes: the cranial, middle, 


$$
\begin{aligned}
& \text { Abbreviations and Acronyms } \\
& \text { BrdU }=\text { bromodeoxyuridine } \\
& \text { HGF }=\text { hepatocyte growth factor } \\
& \text { hKGF }=\text { human keratinocyte growth factor } \\
& \text { HRP }=\text { horseradish peroxidase } \\
& \text { KGF }=\text { keratinocyte growth factor } \\
& \text { KGFR }=\text { keratinocyte growth factor receptor } \\
& \text { PCR }=\text { polymerase chain reaction } \\
& \text { SP-A }=\text { surfactant protein-A }
\end{aligned}
$$

accessory and caudal lobes. In the surgery group the right 3 lobes (cranial, middle, and accessory lobe) were excised by means of thoracotomy, and the remaining caudal lobe was used for investigation. In the sham group a simple right thoracotomy was performed. Each experimental group at a given time point consisted of 3 rats. The remaining lung lobe after trilobectomy and sham operation was dissected out and fixed in $4 \%$ paraformaldehyde (Merck, Darmstadt, Germany). Serial 4- $\mu \mathrm{m}$ sections were cut, and each specimen was stained with hematoxylin and eosin. All animal experiments were performed in accordance with National Institutes of Health guidelines dictated by the Animal Care Facility at Nagasaki University Graduate School of Medicine (approval code 0309010318).

\section{Cells}

L2 rat lung epithelial cells (ATCC, Manassas, Va) were grown in F12K medium (Sigma, St Louis, Mo) supplemented with $100 \mathrm{U} / \mathrm{mL}$ penicillin, $100 \mathrm{mg} / \mathrm{mL}$ streptomycin, and $10 \%$ fetal bovine serum at $37^{\circ} \mathrm{C}$ and $5 \% \mathrm{CO}_{2}$.

\section{Construction of a Recombinant Plasmid Encoding Human KGF}

The human $K G F(\mathrm{~h} K G F)$ coding region was amplified by means of polymerase chain reaction (PCR), with pCEV9 plasmid (kindly provided by Jeffrey Rubin, National Cancer Institute, Bethesda, Md) as a template. This plasmid contains the complete $K G F$ coding sequence isolated from an M426 human embryonic lung fibroblast cDNA library. ${ }^{7}$ The sequences of forward and reverse primers were $5^{\prime}$-CCTAGATCTGCCACCATGCA CAAATGGATACTGAC- $3^{\prime}$ and $5^{\prime}$-CCTCTCGAGTTAAGTTATTGC CATAGGAAG- $3^{\prime}$, respectively. The forward primer is homologous to nucleotides 1 to 20 in the $\mathrm{h} K G F$ open reading frame and contains a consensus (GCCACC) Kozak sequence immediately upstream of the initiation codon. In addition, a $B g l$ II site was inserted at the $5^{\prime}$-end to facilitate cloning. The reverse primer is homologous to nucleotides 563 to 582 and contains an $X b a \mathrm{I}$ site at the $5^{\prime}$-terminus. These primers allowed amplification of a 603-bp cDNA fragment. PCR was carried out in a reaction mixture containing $2 \mathrm{mmol} / \mathrm{L}$ Tris- $\mathrm{HCl}$ (pH 8.0), $10 \mathrm{mmol} / \mathrm{L} \mathrm{KCl}, 2 \mathrm{mmol} / \mathrm{L} \mathrm{MgCl}_{2}$, $0.01 \mathrm{mmol} / \mathrm{L}$ ethylenediamine tetra-acetic acid, $0.1 \mathrm{mmol} / \mathrm{L}$ dithiothreitol, $0.05 \%$ Tween $20,0.05 \%$ Nonidet P- $40,5 \%$ glycerol, $0.25 \mathrm{mmol} / \mathrm{L}$ deoxyribonucleoside triphosphate mixture, $100 \mathrm{pmol}$ of each primer, $6 \mu \mathrm{g}$ of pCEV9 DNA, and $3 \mathrm{U}$ of Taq polymerase (Takara Mirus Bio Co, Shiga, Japan). Before cycling, the mixture was divided into four $20-\mu \mathrm{L}$ reaction volumes. PCR assays were performed in a Gene Amp PCR system 9600 (Perkin Elmer, Foster City, Calif) for 27 cycles under the following conditions: $94^{\circ} \mathrm{C}$ for 30 seconds, $54^{\circ} \mathrm{C}$ for 30 seconds, and $72^{\circ} \mathrm{C}$ for 1 minute, followed by a final extension at $72^{\circ} \mathrm{C}$ for 15 minutes. Agarose gel electrophoresis with a Qiagen Gel Extraction Kit (Qiagen, Hilden, Germany) was used to purify the amplified product. The recovered DNA was then cloned into the plasmid pGEM-T Easy Vector by using the pGEM-T Easy Vector System I (Promega, Madison, Wis), resulting in the pGEM-hKGF plasmid. We then isolated the DNA insert containing the $\mathrm{h} K G F$ sequence from



subcloned into the p3xFLAG-CMV14 vector (Sigma) at the same restriction sites to produce the $\mathrm{pKGF-FLAG} \mathrm{plasmid.} \mathrm{All} \mathrm{constructions} \mathrm{were} \mathrm{con-}$ firmed by means of automated sequencing (CEQ8000; Beckman Coulter, Fullerton, Calif).

\section{Evaluation of Lung Cell Proliferation}

Lung cell proliferation was analyzed immunohistochemically by using anti-proliferating cell nuclear antigen (PCNA) antibody (DAKO, Glostrup, Denmark). Briefly, the sections were autoclaved and incubated with PCNA (1:200) as the primary antibody and horseradish peroxidase (HRP)-goat anti-mouse $\operatorname{IgG}(1: 200)$ (Chemicon International Temecula, Calif) as the secondary antibody.

\section{Western Blot Analysis of KGF and KGFR Expression in Transfected Cells and Remaining Lung Tissue}

Transfected cells were lysed in $0.3 \mathrm{~mL}$ of lysis buffer $(50 \mathrm{mmol} / \mathrm{L}$ Tris$\mathrm{HCl}$ [pH 7.4], $150 \mathrm{mmol} / \mathrm{L} \mathrm{NaCl}, 5 \mathrm{mmol} / \mathrm{L}$ ethylenediamine tetra-acetic acid, $1 \mathrm{mmol} / \mathrm{L}$ phenylmethylsulfonyl fluoride, $50 \mu \mathrm{g} / \mathrm{mL}$ lima bean trypsin inhibitor, and $0.5 \%$ Triton X-100). Rat lung specimens were homogenized in lysis and centrifuged, and then the supernatants were collected. Recombinant human KGF (Pepro Tech EC, London, UK) and recombinant human KGFR (R\&D Systems Minneapolis, Minn) were also processed as positive controls. Samples were separated by means of sodium dodecylsulfate-polyacrylamide gel electrophoresis on a $4 \%$ to $20 \%$ gradient gel (Daiichi Pure Chemicals, Tokyo, Japan) for KGF or a $10 \%$ to $20 \%$ gradient gel (Daiichi) for KGFR and electrophoretically transferred to a polyvinylidene difluoride membrane (Immobilon; Millipore Corp, Bedford, Mass). The membranes were blocked with Blocking One (Nacalai tesque, Kyoto, Japan) and then incubated with the first antibody (1:800 anti-KGF antibody, 1:800 antiKGFR antibody; Nichirei Co, Tokyo, Japan; and 1:6000 peroxidase-conjugated mouse monoclonal anti-FLAG antibody, Invitrogen, Tokyo, Japan). After washing, the membranes were reacted with HRP-conjugated goat anti-rabbit IgG as the secondary antibody at 1:8000 for KGF and 1:4000 for KGFR and were visualized by means of chemiluminescence with the ECL Plus reagent (Amersham Biosciences, Piscataway, NJ).

\section{Immunohistochemistry of KGF and KGFR in the Lung}

Immunohistochemistry was performed to determine the expression of KGF and KGFR in tissue sections by using anti-KGF and anti-KGFR antibodies, as described previously. ${ }^{8,9}$ Sections of rat lung tissue were incubated for 2 hours with primary antibody at $1.0 \mu \mathrm{g} / \mathrm{mL}$ for the anti-KGF antibody and 1:600 for anti-KGFR antiserum and then incubated with HRP-conjugated goat anti-rabbit IgG (1:100; MBL, Nagoya, Japan) for 1 hour. After washing, HRP sites were visualized by treatment with 3,3'-diaminobenzidine- $4 \mathrm{HCl}$ (Dojindo, Kumamoto, Japan) and $\mathrm{H}_{2} \mathrm{O}_{2}$.

\section{Transfection of KGF Expression Plasmid Into Cultured Cells and Assay of Cell Proliferation and KGF Production}

L2 cells $\left(2 \times 10^{6}\right.$ in $\left.200 \mu \mathrm{L}\right)$ were resuspended into sterile cuvettes, and plasmid DNA $(10 \mu \mathrm{g})$ of pKGF-FLAG or pFLAG genes was added. An electric pulse ( $400 \mathrm{~V}, 99 \mu \mathrm{s}, 5$ pulses) was delivered to the cells with a BTX Transfector apparatus (BTX, Inc, San Diego, Calif). Cells were plated at a density of $3 \times 10^{3}$ cells/well in 96 -well plates at a final volume of $100 \mu \mathrm{L} /$ well and cultured in a humidified atmosphere at $37^{\circ} \mathrm{C}$ for analysis with the Cell Proliferation Biotrak enzyme-linked immunosorbent assay system (Amersham Biosciences) to determine the biologic activity of KGF-FLAG fusion protein in vitro. The optical density of each well was measured at $450 \mathrm{~nm}$.

The cells were plated at a density of $5 \times 10^{5}$ cells/well in 6-well plastic culture dishes (Iwaki, Tokyo, Japan) in $1 \mathrm{~mL}$ of F12K medium (Sigma) 


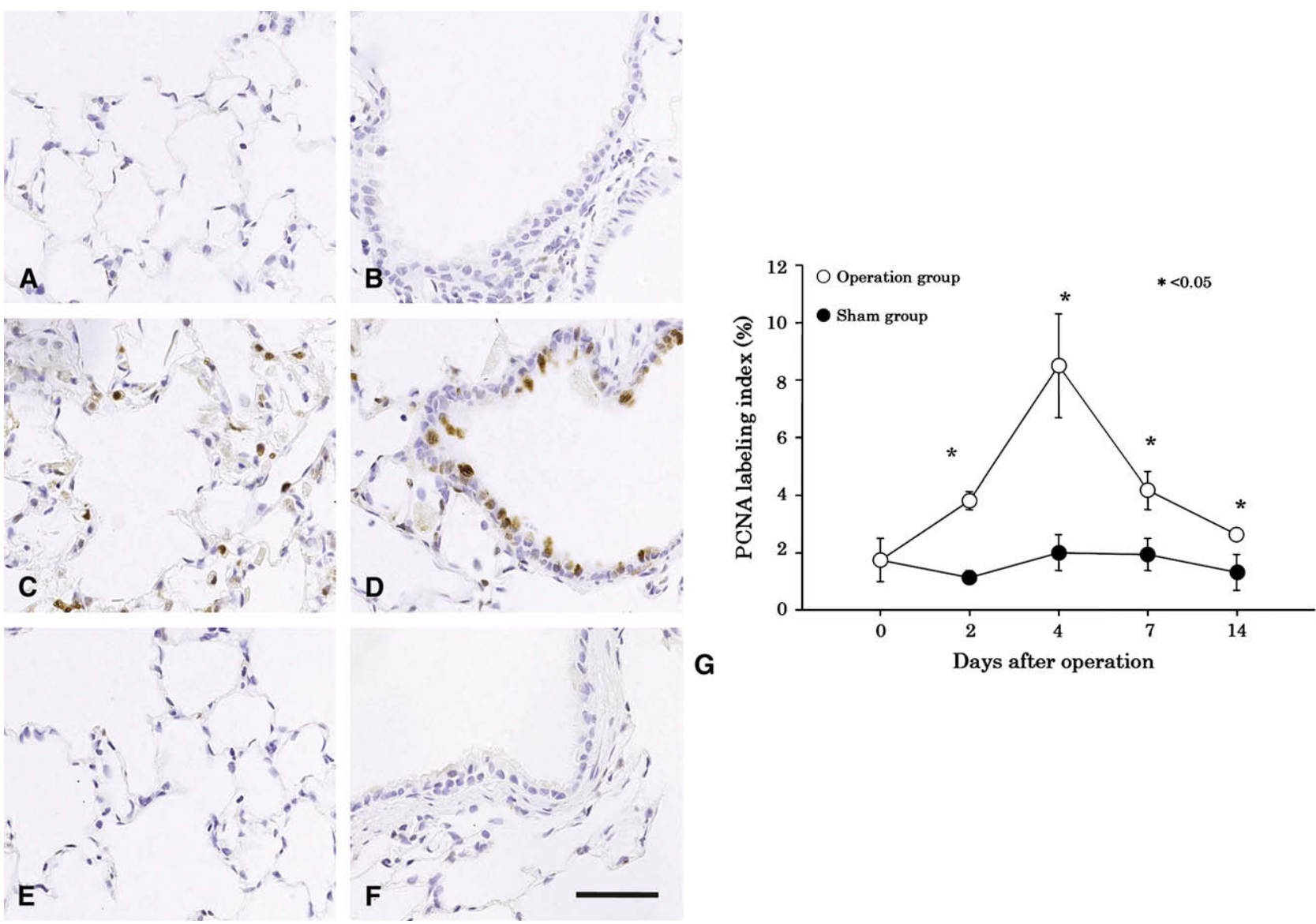

FIGURE 1. Serial changes in proliferating cell nuclear antigen (PCNA)-positive alveolar epithelial cell counts in the remaining lung. A-F, Immunohistochemical staining for PCNA. (Original magnification $400 \times$.) Bar $=50 \mu \mathrm{m}$. A, Alveolar part of normal lung. B, Bronchial part of normal lung. C, Alveolar part at day 4 after trilobectomy. D, Bronchial part at day 4 after trilobectomy. E, Alveolar part at day 4 after the sham operation. F, Bronchial part at day 4 after the sham operation. G, Serial changes in proliferating cell nuclear antigen labeling index. Open circles, Trilobectomy group $(\mathrm{n}=3)$; filled circles, sham group $(\mathrm{n}=3) . * P<.05$.

supplemented with $10 \%$ fetal bovine serum per well to measure KGF. After incubation for 24,48 , or 72 hours, the media were collected, and the cells were harvested with a lysate buffer $(1 \%$ sodium dodecylsulfate and 1.0 $\mathrm{mmol} / \mathrm{L}$ sodium orthovanadate in $10 \mathrm{mmol} / \mathrm{L}$ Tris- $\mathrm{HCl}, \mathrm{pH}$ 7.4). The concentration of KGF was determined by means of enzyme-linked immunosorbent assay (R\&D Systems), according to the instructions provided by the manufacturer.

\section{In Vivo Transfection of KGF-FLAG and FLAG Expression Vectors}

For tissue transfection, pulses generated with an Electro Square Porator (T820; BTX, Inc) were delivered to the organ by a pair of electrode disks (1-cm diameter) attached to the tips of tweezers (Pinsettes-Type electrode 449-10PRG; Meiwa Shoji, Tokyo, Japan). We used a green fluorescent protein-expressing plasmid to optimize conditions for lung transfection. The best results were obtained with 6 pulses of $50 \mathrm{~V}$ for $50 \mu$ s, each separated by $999 \mathrm{~ms}$, which were delivered by electrode disks separated by approximately $5 \mathrm{~mm}$ (data not shown). After trilobectomy, a solution of $100 \mu \mathrm{g}$ of pKGF-FLAG or pFLAG plasmid in $100 \mu \mathrm{L}$ of PBS was injected directly with a 29-gauge needle into the remaining lung between the electrode disks. Immediately after the DNA injection, electric pulses were administered. Rats were killed 2, 4, or 7 days after electroporation. Each experimental group consisted of 5 rats at each time point.

\section{Identification of PCNA-Positive and FLAG-Expressing Cell Types}

Double staining for PCNA and surfactant protein-A (SP-A), an alveolar type II epithelial cell marker, was performed on sections of lung tissue to identify the types of PCNA-positive cells. The slides were stained first with anti-SP-A antibody (1:30; Santa Cruz Biotechnology, Santa Cruz, Calif), and the HRP sites were visualized with $3,3^{\prime}$-diaminobenzidine- $4 \mathrm{HCl}$ and $\mathrm{H}_{2} \mathrm{O}_{2}$. The slides were autoclaved and immersed 3 times with 0.1 mol/L glycine- $\mathrm{HCl}$ buffer $(\mathrm{pH} 2.2)$ and then immunostained with antiPCNA antibody (1:50), as described above. HRP reactivity was visualized with 4-Cl-1-naphthol (Tokyo Kasei Kogyo, Tokyo, Japan). Peroxidase-conjugated mouse monoclonal anti-FLAG antibody (1:30, Invitrogen) was used to identify FLAG-expressing cells.

\section{Quantitative Analysis}

The PCNA staining was graded as positive or negative compared with the negative control. For each section, more than 2000 cell nuclei were counted over randomly selected fields at $400 \times$ magnification. The number of positive cells was expressed as the percentage of cells with positive nuclei per total number of counted nuclei. ${ }^{10}$ The signal density of KGF and KGFR per cell was measured by using an image analyzer and calculated from the sum of the gray values of all pixels corresponding to the cell. 
By using a grid with lines of known length, the average airspace distance (mean linear intercept) was determined in 30 randomly selected microscopic fields per rat in pFLAG gene- or pKGF-FLAG gene-transfected groups at day 7 after the operation. The observers who performed the measurements were blinded to the experimental groups.

\section{Statistical Analysis}

Data are expressed as mean values \pm the standard error of the mean. Differences between groups were examined for statistical significance with the unpaired Student's $t$ test or 1-way analysis of variance. All analyses were performed with a statistical software package (StatView, version J5.0; Abacus Concepts, Berkeley, Calif).

\section{RESULTS}

\section{Induction of Epithelial Cell Proliferation in} Remaining Lung After Trilobectomy

Proliferating cells were assessed by means of immunochemical staining for PCNA to examine the cell kinetics of compensatory regenerating lung. A few proliferating cells were noted in the normal lung (Figure 1, $A$ and $B$ ), with a PCNA labeling index (percentage of proliferative cells per total cell number) of $1.74 \% \pm 0.75 \%$ for alveolar epithelial cells. At day 4 after trilobectomy, several PCNA-positive bronchial and alveolar epithelial cells were noted (Figure 1, $C$ and $D$ ), with a PCNA labeling index of 8.49 \pm 1.83 for alveolar epithelial cells. In the sham-operated lungs, few PCNA-positive bronchial and alveolar epithelial cells were detected (Figure 1, $E$ and $F$ ), with a PCNA labeling index of $1.99 \pm 0.61$ for alveolar epithelial cells. Most of the positive cells in the alveolar regions of rats undergoing trilobectomy seemed to be alveolar type II epithelial cells (Figure 1,C). As shown in Figure 1, $G$, the percentage of PCNA-positive cells increased significantly at day 2 and reached a maximum at day 4 after the operation in the trilobectomy group. Many PCNA-positive cells were alveolar type II cells (Figure 1,C); however, some alveolar type I cells, macrophages, fibroblasts, and bronchial epithelial cells were PCNA positive.

\section{Western Blot Analysis of KGF and KGFR Expression in Remaining Lung After Trilobectomy}

Western blot analysis showed specific bands corresponding to KGF and KGFR proteins at approximately 28 and $130 \mathrm{kd}$, respectively. ${ }^{3,11,12}$ The approximate molecular mass of $130 \mathrm{kd}$ is in agreement with the reported molecular mass of the mature KGFR. ${ }^{11-13}$ Recombinant human KGF is an 18.9-kd protein containing 163 amino acid residues but has the same function as endogenous KGF. The reduced human KGFR has a calculated molecular mass of approximately $56 \mathrm{kd}$. As a result of glycosylation, the recombinant protein migrates as an approximately $100-\mathrm{kd}$ protein in sodium dodecylsulfate-polyacrylamide gel electrophoresis. The intensity levels of the KGF and KGFR bands in the remaining lung markedly increased at day 4 after trilobectomy

\section{$28 \mathrm{kDa} \rightarrow$}



FIGURE 2. Western blot analysis of keratinocyte growth factor and keratinocyte growth factor receptor in the remaining lung. Recombinant human keratinocyte growth factor protein (lane 1) and lysates of remaining lung at day 4 after trilobectomy (lane 2) and after the sham operation (lane 3) are shown. Recombinant human keratinocyte growth factor receptor protein (lane 4) and lysates of remaining lung at day 4 after trilobectomy (lane 5) and after the sham operation (lane 6) are also shown.

compared with those seen in the sham-operated group (Figure 2).

\section{Immunohistochemical Localization of KGF and KGFR in Remaining Lung After Trilobectomy}

Normal lung tissue collected after the sham operation showed KGF protein expression only in a few stromal cells and alveolar epithelial cells, particularly alveolar type II cells (data not shown). KGFR was also found in only a few epithelial cells. The expression of both KGF and KGFR increased after trilobectomy compared with that seen in the sham-operated lungs (Figure 3, $B$ and $D$ ) and reached a maximum in the alveolar (Figure 3, $A$ and $C$ ) and bronchial (Figure 3, $E$ and $F$ ) regions at day 4 after the operation. KGF was expressed strongly in stromal cells and alveolar type I and type II cells, whereas KGFR was expressed only in epithelial cells, especially alveolar type II cells, where the signal was distributed in the cytoplasm and plasma membrane. KGF expression increased as early as day 2 after trilobectomy in the remaining lung (signal density in the operation group, $3.92 \pm 1.05$-fold; sham operation group, $1.05 \pm 1.11$-fold; $P<.05$ ) and reached a maximum at day 4 after the operation (signal density in the operation group, $9.16 \pm 4.38$-fold; sham operation group, $0.84 \pm 0.33$-fold; $P<.05$ ), as shown in Figure 3, G. Similarly, KGFR expression reached a maximum at day 4 after trilobectomy (signal density in the operation group, $22.96 \pm 13.6$-fold; sham operation group, 0.91 \pm 0.30 -fold; $P<.05$ ), as shown in Figure 3, $H$.

To clarify the relationship between PCNA-positive cells and KGF- or KGFR-positive cells, these antigens were localized in serial sections (Figure 4). KGF and KGFR were detected in both alveolar type I and type II cells, whereas PCNA was localized in alveolar type II cells. 

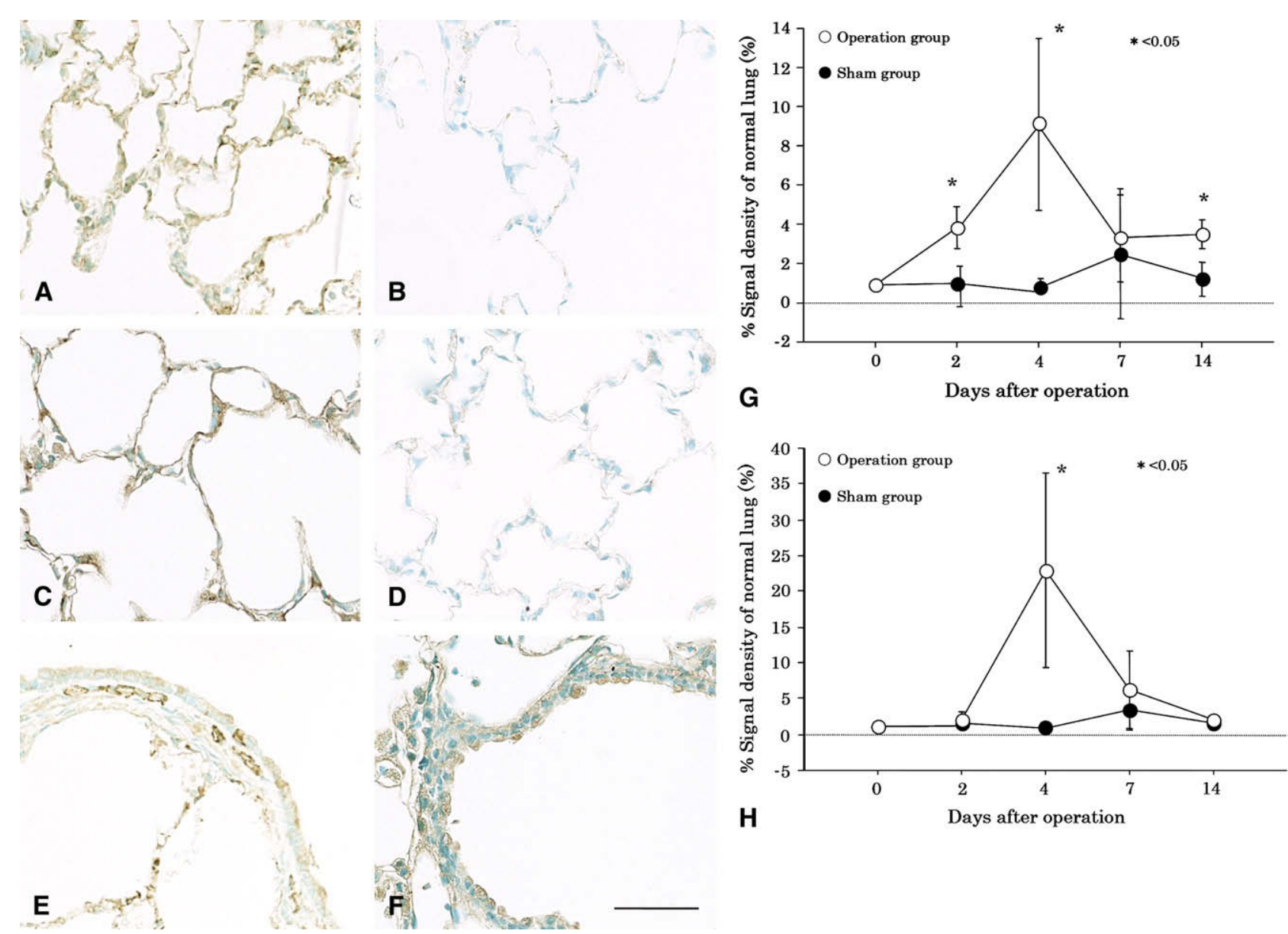

FIGURE 3. Immunohistochemical detection of keratinocyte growth factor and keratinocyte growth factor receptor in the remaining lung after trilobectomy. The expression of keratinocyte growth factor (A, B, and E) and keratinocyte growth factor receptor (C, D, and F) was detected by means of immunohistochemistry. A, Alveolar part at day 4 after trilobectomy. B, Alveolar part at day 4 after the sham operation. C, Alveolar part at day 4 after trilobectomy. D, Alveolar part at day 4 after the sham operation. E, Bronchial part at day 4 after trilobectomy. F, Bronchial part at day 4 after trilobectomy (Original magnification $400 \times$.) Bar $=50 \mu \mathrm{m}$. G. Serial changes in the signal density of keratinocyte growth factor staining in the trilobectomy group $(\mathrm{n}=3$, open circles $)$ and the sham operation group $(\mathrm{n}=3$, filled circles $)$. H, Serial changes in the signal density of keratinocyte growth factor receptor staining in the trilobectomy group $(\mathrm{n}=3$, open circles $)$ and the sham operation group $(\mathrm{n}=3$, filled circles $)$.

\section{Enhancement of KGF Expression and Proliferating Activity in Cultured Rat Lung Epithelial Cells (L2 Cells) Expressing pKGF-FLAG Gene}

L2 cells were transfected with pKGF-FLAG cDNA, and the concentration of KGF-FLAG protein in the lysates and culture medium was measured at various time points (Figure 5, A). KGF concentrations in the medium increased in a time-dependent manner, whereas those in the lysate were unchanged.

Next, bromodeoxyuridine (BrdU) uptake by L2 cells transfected with pKGF-FLAG or pFLAG plasmids was measured to assess the DNA synthetic activity (Figure 5, $B)$. After 24 hours of transfection, BrdU uptake increased significantly in pKGF-FLAG-transfected cells (1.28 \pm 0.04 -fold; $P=.0003$ ), although there was no significant difference in cell numbers (Figure 5, $C$ ). After 72 hours, however, the increase in cell numbers became significant
(pFLAG, $31.3 \pm 3.1 \times 10^{4}$ cells; pKGF-FLAG, $42.1 \pm$ $2.1 \times 10^{4}$ cells; $P=.048$ ) (Figure 5, $C$ ), whereas no significant difference was measured in the rate of BrdU uptake. These results indicated that the KGF expression vector used in the present study worked well in lung epithelial cells and that the expressed KGF was active in stimulating cell proliferation.

\section{Effect of Augmented KGF Expression Driven by pKGF-FLAG Transfection on Compensatory Growth of Remaining Lung After Trilobectomy}

PCNA expression was then examined in the remaining lung transfected with pKGF-FLAG or pFLAG after trilobectomy to assess the effect of prolonged exposure to KGF on compensatory lung growth process. As shown in Figure 6, $A$ and $B$, the number of PCNA-positive cells markedly increased in the remaining lung transfected with pKGF-FLAG compared with 

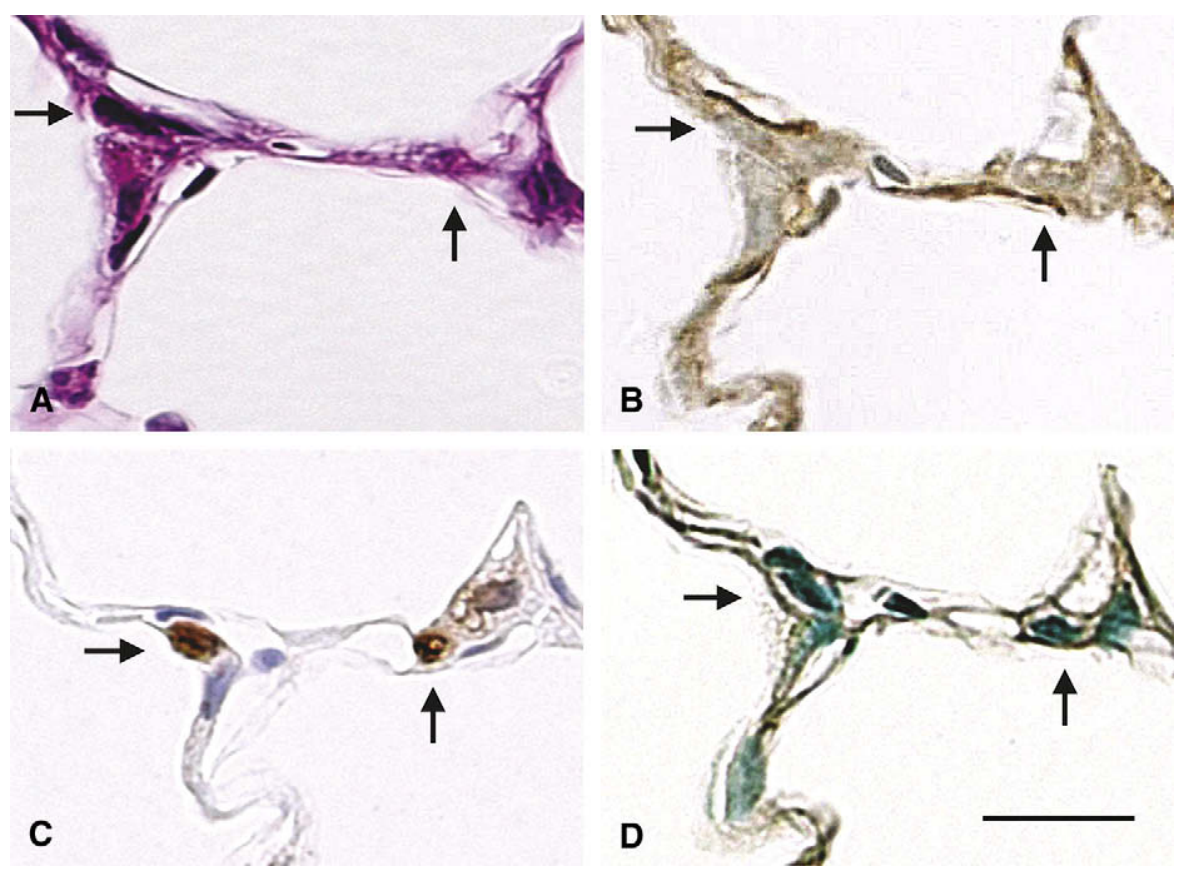

FIGURE 4. Immunohistochemical detection of keratinocyte growth factor, keratinocyte growth factor receptor, and proliferating cell nuclear antigen in serial sections of the remaining lung at day 4 after trilobectomy. A, Hematoxylin and eosin staining. B, Keratinocyte growth factor was detected in the cytoplasm of alveolar epithelial cells. C, Proliferating cell nuclear antigen staining. D, Keratinocyte growth factor receptor was detected in the plasma membrane of alveolar epithelial cells. Proliferating cell nuclear antigen-positive alveolar type II cells are identical, at least in part, to keratinocyte growth factor and keratinocyte growth factor receptor double-positive cells (arrows). Bar $=25 \mu \mathrm{m}$.

that overexpressing pFLAG alone. In fact, immunohistochemistry of the pKGF-FLAG-transfected lung revealed a higher abundance of PCNA-positive cells (Figure 6, D) in areas strongly stained for FLAG (Figure $6, C$ ) than in FLAG-negative areas (data not shown). Quantitative analysis of PCNA-positive cells also revealed a significant increase in the remaining lung transfected with pKGFFLAG (d2, pFLAG, $10.8 \pm 2.1 \%$; pKGF-FLAG, $18.8 \pm$ $1.1 ; P=.01, \mathrm{~d} 4$, pFLAG, $11.7 \pm 0.8 \%$; pKGF-FLAG, $18.4 \pm 0.8 ; P=.005$ ) (Figure $6, E$ ). Figure $6, F$, shows mean linear intercept values measured in the 2 experimental groups at day 7 after the operation. Rats transfected with the pKGF-FLAG gene (pFLAG, $57.5 \pm 0.9 \mu \mathrm{m}$; pKGF-FLAG, $49.1 \pm 0.7 \mu \mathrm{m} ; P=.001$ ) showed a significant decrease in the mean values of mean linear intercept compared with rats transfected with the pFLAG gene.

Finally, PCNA-positive cells in the pKGF-FLAG-transfected lung comprised predominantly alveolar epithelial cells, with some fibroblasts, endothelial cells, macrophages, and bronchial epithelial cells. To correlate the PCNA-positive cells with alveolar epithelial cell type, we double-stained for PCNA and SP-A (a marker for alveolar type II cells). SPA-positive cells also expressed PCNA. Interestingly, however, some SP-A-negative epithelial cells were also positive for PCNA, indicating that alveolar type I cells could proliferate under these experimental conditions (Figure 7). Interestingly, in the remaining lung after trilobectomy only, a few cells excluding alveolar type II cells were proliferative (Figure $1, C)$. However, in the remaining lung after trilobectomy and gene transfection, many cells, including type I cells, macrophages, fibroblasts, and bronchial cells, were proliferating, especially alveolar type II cells (Figure 6, $B$ and $D$ ).

\section{DISCUSSION}

The present study investigated the possible roles of KGF in the regulation of rat lung compensatory growth after right trilobectomy and found that in parallel with more PCNApositive alveolar type II cells, the expression levels of KGF and KGFR were increased in the remaining lung. In particular, the expression of KGFR was markedly induced after trilobectomy in alveolar epithelial cells, and such expression might be involved in the induction of proliferation of alveolar type II cells. Moreover, when the KGF-FLAG expression vector was expressed in the remaining lung by means of electroporation, the fusion protein was effectively produced in various cells. In addition, the transfected lung showed significantly enhanced proliferative activity and possible alveolar septation. These results strongly implicate KGF in the induction of alveolar epithelial cell proliferation for compensatory growth of the lung and that in vivo overexpression of KGF seems to accelerate KGF-dependent compensatory growth processes in organs.

A number of studies have documented that pulmonary alveoli are capable of regeneration. Among rodents, retinoid 

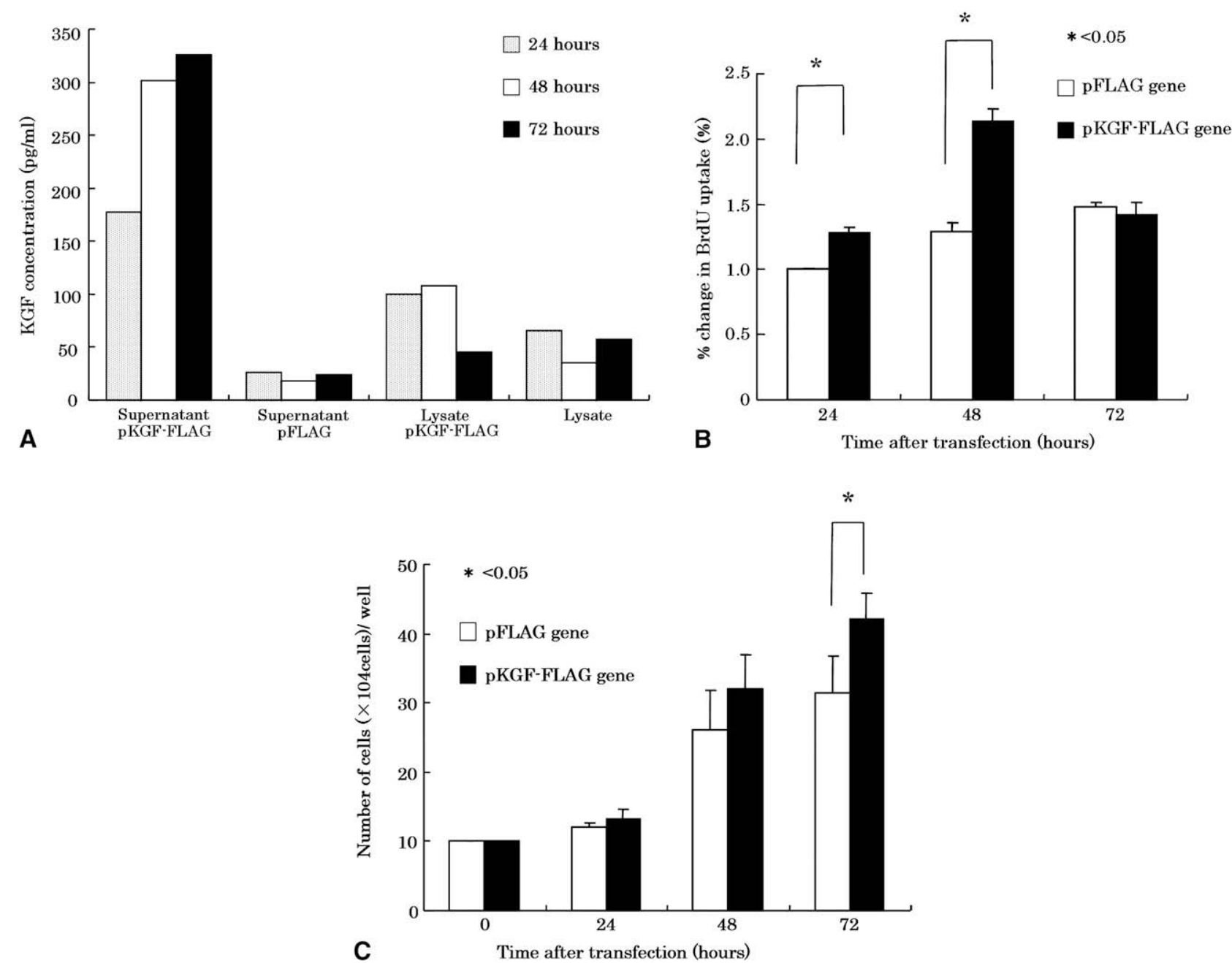

FIGURE 5. Keratinocyte growth factor protein production, DNA synthesis, and cell proliferation in cell medium and lysate transfected with the pKGFFLAG gene and the pFLAG gene. A, The concentrations of keratinocyte growth factor in the medium and lysates of L2 cells transfected with the pKGFFLAG gene and the pFLAG gene were measured at 24,48 , and 72 hours after transfection. The keratinocyte growth factor concentration in the medium of L2 cells transfected with the pKGF-FLAG gene increased in a time-dependent manner. B and C, DNA synthesis (B) and cell proliferation (C) of L2 cells transfected with pKGF-FLAG and pFLAG. L2 cells were transfected by means of electroporation; cultured for 24, 48, and 72 hours; and subsequently assessed for bromodeoxyuridine uptake, as well as the number of cells per well. There were significant differences in bromodeoxyuridine uptake between the pKGF-FLAG gene and the pFLAG gene at 24 and 48 hours after transfection. There was also a significant difference in the cell numbers between the pKGFFLAG gene and the pFLAG gene at 72 hours after transfection.

acid enhanced lung growth after pneumonectomy in rats, ${ }^{1}$ and estradiol induced alveolar regeneration after loss of alveoli induced by ovariectomy in adult mice. ${ }^{14}$ These studies described increased cell proliferation, lung volume, lung weight, alveolar surface density, and alveolar numbers in experimental animals. Unfortunately, it is impossible to conduct the above assessments in human subjects; instead, these tests are limited to pulmonary function tests, especially measurement of forced vital capacity and forced expiratory volume in 1 second. Thus there is thus far no documented evidence for lung regeneration in human subjects. However, based on the present and previous animal experiments, further advances in medical biotechnology could perhaps allow investigation of this process in human subjects.
The KGF-KGFR system also plays an important role in lung epithelial cell turnover in normal rodents. Many studies showed that administration of recombinant KGF could mimic the proliferation of alveolar type II cells both in vitro and in vivo. ${ }^{15,16}$ Importantly, Kaza and associates ${ }^{5}$ demonstrated that recombinant KGF enhances postpneumonectomy lung growth accompanied by alveolar cell proliferation, which is similar to the present results. However, they did not deal with the involvement of KGFR, which is also an essential factor in the logical understanding of the role of KGF in compensatory lung growth. The present work demonstrates the involvement of both KGF and KGFR in the induction of compensatory lung growth. In fact, KGF has been implicated in various phenomena ${ }^{8,17}$ in which a low level 

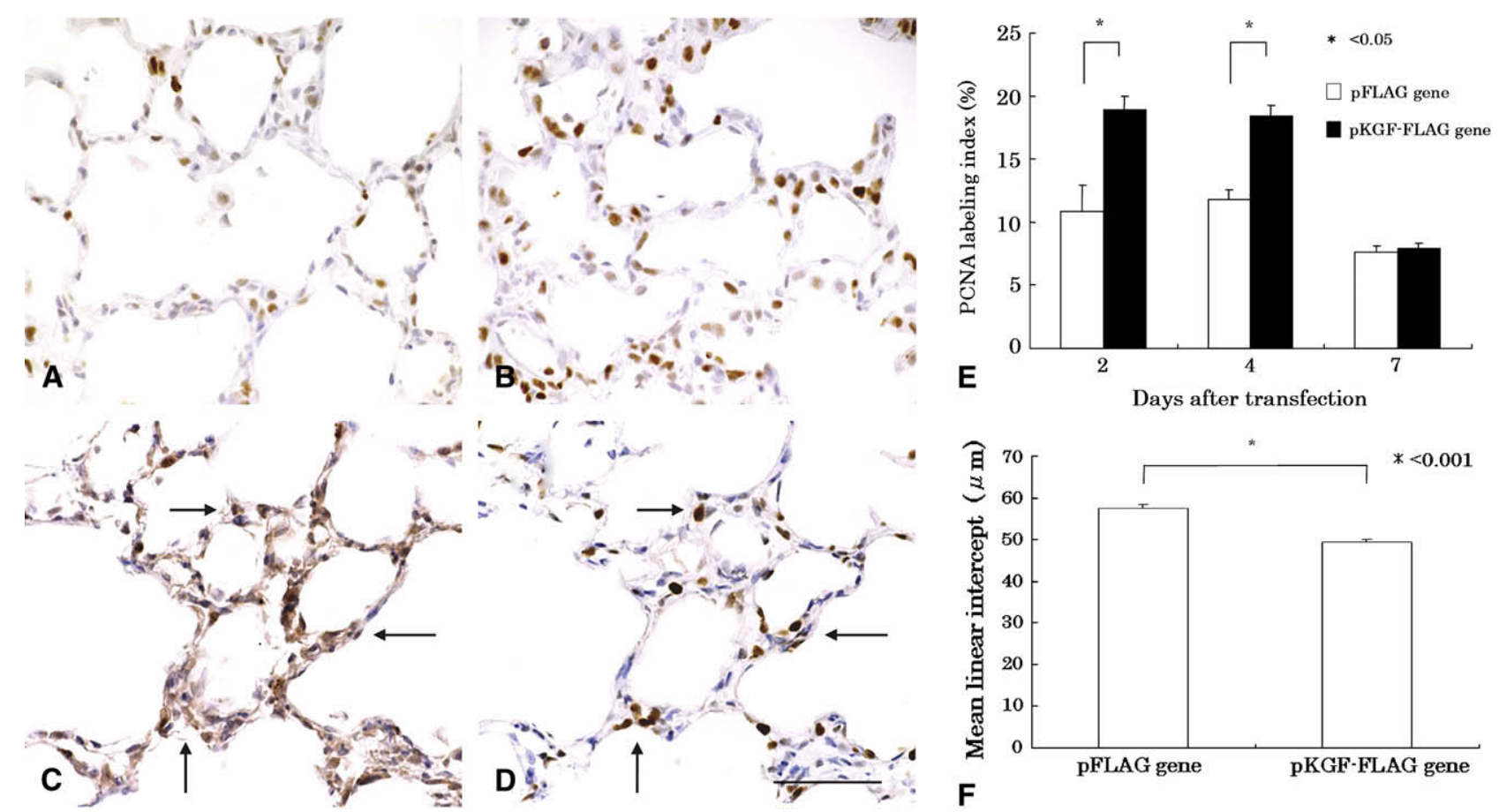

FIGURE 6. Effects of pKGF-FLAG gene and pFLAG gene expression on proliferating cell nuclear antigen (PCNA)-positive cells at day 4 after electroporative transfection. A and B, Immunohistochemistry for proliferating cell nuclear antigen in the alveolar part of the remaining lung transfected with the pFLAG gene (A) or the pKGF-FLAG gene (B). C and D, In adjacent sections of the alveolar part transfected with the pKGF-FLAG gene, one section (C) was used for the detection of FLAG (KGF-FLAG), and another (D) was stained for proliferating cell nuclear antigen expression. (Original magnification $400 \times$.) Bar $=50 \mu \mathrm{m}$. E, Serial changes in proliferating cell nuclear antigen labeling index. Open bars, Group transfected with the $\mathrm{pFLAG}$ gene ( $\mathrm{n}=5$ ); filled bars, group transfected with the pKGF-FLAG gene $(\mathrm{n}=5) . * P<.05$. F, Mean linear intercept values measured in the remaining lung transfected with the pFLAG gene or the pKGF-FLAG gene. Values are presented as means \pm standard error of the mean. $* P<.001$ for comparison of mean linear intercept of the remaining lung transfected with the pKGF-FLAG gene and that with the pFLAG gene.

of constitutive KGFR expression might be sufficient for the necessary action of KGF. The present study showed that PCNA, KGF, and KGFR were simultaneously localized in the same alveolar type II cells at day 4 after trilobectomy. However, there was an apparent difference in the appearance of PCNA- and KGFR-positive cells, and it should be noted that several other factors, such as basic fibroblast growth factor ${ }^{18}$ hepatocyte growth factor (HGF) ${ }^{19,20}$ epidermal growth factor, ${ }^{21}$ and vascular endothelial growth factor, ${ }^{22}$ might also play a role in lung growth.

Basic fibroblast growth factor induces an increase in pulmonary blood flow in the damaged lung. ${ }^{18} \mathrm{HGF}$ is a potent mitogen for rat alveolar epithelial cells, especially alveolar type II cells, ${ }^{19}$ and might work simultaneously on various types of cells. However, HGF alone was found to be incapable of restoring branching morphogenesis, unlike KGF and acidic fibroblast growth factor. HGF exhibits synergistic effects with KGF or acidic fibroblast growth factor in this mesenchyme-free system. ${ }^{20}$ Epidermal growth factor stimulates the cytodifferentiation of alveolar type II cells and biosynthesis of surfactant precursor proteins. ${ }^{21}$ Furthermore, it has been demonstrated that during pulmonary distension, the stimulus for alveolarization (capillary and alveolar growth) upregulated vascular endothelial growth factor mRNA. ${ }^{22}$ Finally, it is unlikely that each of the above factors can singularly enhance lung growth; rather, the synergistic effects of mediators of mesenchymal-epithelial interactions are more likely to be important in lung growth.

The present study applied electroporation to maximize the transfection efficiency so that a single-dose regimen could be used and much smaller amounts of DNA would be required. One major advantage of electroporation for gene transfection into the lung is that it efficiently transfers cDNA to multiple cell types simultaneously, including alveolar epithelial cells, bronchial epithelial cells, smooth muscle cells, endothelial cells, and other cells in focal or target areas of the lung. In the present study, in the remaining lung after trilobectomy only, a few cells, excluding alveolar type II cells, were proliferative (Figure 1,C); however, in the remaining lung after trilobectomy and gene transfection, many cells, including type I cells, macrophages, fibroblasts, and bronchial cells, were proliferative, especially alveolar type II cells (Figure 6, $B$ and $D$ ).

The significantly increased PCNA index in the remaining lung after trilobectomy was seen by day 2 after transfection and continued until day 4 before returning to the control 


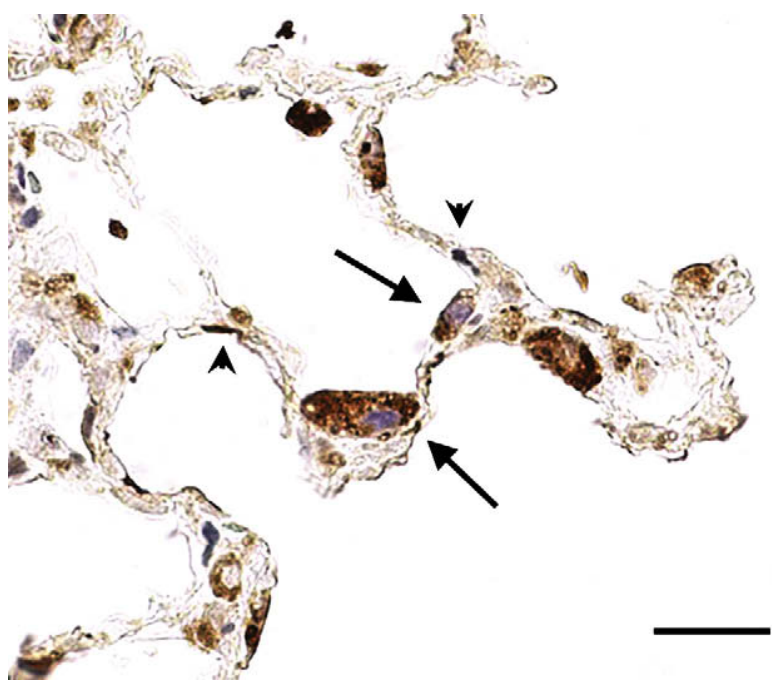

FIGURE 7. Double staining for proliferating cell nuclear antigen and surfactant protein-A at day 4 after transfection in the alveolar part of the remaining lung transfected with the pKGF-FLAG gene. Double staining for proliferating cell nuclear antigen (blue) and surfactant protein-A (brown). The majority of proliferating cell nuclear antigen-positive cells were epithelial cells. Arrows, Alveolar type II cells; arrowhead, type I cells. (Original magnification $400 \times$ ). Bar $=25 \mu \mathrm{m}$.

untransfected level at day 7. Yew and coworkers ${ }^{23}$ reported increased duration of expression of up to 3 months with a human ubiquitin B promoter or a hybrid cytomegalovirusubiquitin B promoter. In the present study we are not sure whether a long-term expression of KGF is beneficial. However, these alternative promoters might be tested for their effects on both the duration and level of gene expression in our system. On the other hand, at day 7 after the operation, rats transfected with the pKGF-FLAG gene showed a significant decrease in the mean values of mean linear intercept compared with rats transfected with the pFLAG gene $(P<$ .001). In spite of the short duration of gene expression, these data support the possibility of alveolar septation and increased number of alveoli in the pulmonary parenchyma.

In conclusion, our results showed the potential involvement of endogenous KGF in compensatory tissue growth in adult rat lungs. Moreover, direct injection of naked DNA coupled with electroporation seemed to significantly enhance compensatory lung growth. Although more work needs to be done, we believe this study advocates gene therapy as a potential tool to accelerate tissue growth in adult rat lungs.

We thank Dr Jeffrey S. Rubin from the National Cancer Institute/CCR/LCMB, for providing the human $K G F$ cDNA construct.

\section{References}

1. Kaza AK, Kron IL, Kern JA, Long SM, Fiser SM, Nguyen RP, et al. Retinoic acid enhances lung growth after pneumonectomy. Ann Thorac Surg. 2001;71: 1645-50.
2. Voswinckel R, Motejl V, Fehrenbach A, Wegmann M, Mehling T, Fehrenbach H, et al. Characterisation of post-pneumonectomy lung growth in adult mice. Eur Respir J. 2004;24:524-32.

3. Rubin JS, Osada H, Finch PW, Taylor WG, Rudikoff S, Aaronson SA. Purification and characterization of a newly identified growth factor specific for epithelial cells. Proc Natl Acad Sci U S A. 1989;86:802-6.

4. Barton CC, Bucci TJ, Lomax LG, Warbritton AG, Mehendale HM. Stimulated pulmonary cell hyperplasia underlies resistance to $\alpha$-naphthylthiourea. Toxicology. 2000;143:167-81.

5. Kaza AK, Kron IL, Leuwerke SM, Tribble CG, Laubach VE. Keratinocyte growth factor enhances post-pneumonectomy lung growth by alveolar proliferation. Circulation. 2002;106(suppl 1):I120-4.

6. Suzuki T, Shin BC, Fujikura K, Matsuzaki T, Takata K. Direct gene transfer into rat liver cells by in vivo electroporation. FEBS Lett. 1998;425:436-40.

7. Finch PW, Rubin JS, Miki T, Ron D, Aaronson SA. Human KGF is FGF-related with properties of a paracrine effector of epithelial cell. Science. 1989;245:752-5.

8. Yamayoshi T, Nagayasu T, Matsumoto K, Abo T, Hishikawa Y, Koji T. Expression of keratinocyte growth factor/fibroblast growth factor-7 and its receptor in human lung cancer: correlation with tumour proliferative activity and patient prognosis. J Pathol. 2004;204:110-8.

9. Yamamoto-Fukuda T, Aoki D, Hishikawa Y, Kobayashi T, Takahashi H, Koji T. Possible involvement of keratinocyte growth factor and its receptor in enhanced epithelial-cell proliferation and acquired recurrence of middle-ear cholesteatoma. Lab Invest. 2003;83:123-36.

10. Shukuwa K, Izum S, Hishikawa Y, Ejima K, Inoue S, Muramatsu M, et al. Diethylstilbestrol increases the density of prolactin cells in male mouse pituitary by inducing proliferation of prolactin cells and transdifferentiation of gonadotropic cells. Histochem Cell Biol. 2006;126:111-23.

11. Miki T, Bottaro DP, Fleming TP, Smith CL, Burgess WH, Chan AM, et al. Determination of ligand-binding specificity by alternative splicing: two distinct growth factor receptors encoded by a single gene. Proc Natl Acad Sci U S A. 1992;89:246-50.

12. Post M, Souza P, Liu J, Tseu I, Wang J, Kuliszewski M, et al. Keratinocyte growth factor and its receptor are involved in regulating early lung branching. Development. 1996;122:3107-15.

13. Dell KR, Williams LT. A novel form of fibroblast growth factor receptor 2. Alternative splicing of the third immunoglobulin-like domain confers ligand binding specificity. J Biol Chem. 1992;267:21225-9.

14. Massaro D, Massaro GD. Estrogen regulates pulmonary alveolar formation, loss, and regeneration in mice. Am J Physiol Lung Cell Mol Physiol. 2004;287: L1154-9.

15. Ulich TR, Yi ES, Longmuir K, Yin S, Blitz R, Morris CF, et al. Keratinocyte growth factor is a growth factor for type II pneumocytes in vivo. J Clin Invest. 1994;93:1298-306.

16. Panos RJ, Rubin JS, Aaronson SA, Mason RJ. Keratinocyte growth factor and hepatocyte growth factor/scatter factor are heparin-binding growth factors for alveolar type II cells in fibroblast-conditioned medium. J Clin Invest. 1993;92:969-77.

17. Tamaru N, Hishikawa Y, Ejima K, Nagasue N, Inoue S, Muramatsu M, et al. Estrogen receptor-associated expression of keratinocyte growth factor and its possible role in the inhibition of apoptosis in human breast cancer. Lab Invest. 2004;84: 1460-71.

18. Morino S, Nakamura T, Toba T, Takahashi M, Kushibiki T, Tabata Y, et al. Fibroblast growth factor-2 induces recovery of pulmonary blood flow in canine emphysema models. Chest. 2005;128:920-6.

19. Sakamaki Y, Matsumoto K, Mizuno S, Miyoshi S, Matsuda H, Nakamura T. Hepatocyte growth factor stimulates proliferation of respiratory epithelial cells during postpneumonectomy compensatory lung growth in mice. Am J Respir Cell Mol Biol. 2002;26:525-33.

20. Ohmichi H, Koshimizu U, Matsumoto K, Nakamura T. Hepatocyte growth factor (HGF) acts as a mesenchyme-derived morphogenic factor during fetal lung development. Development. 1998;125:1315-24.

21. Foster DJ, Yan X, Bellotto DJ, Moe OW, Hagler HK, Estrera AS, et al. Expression of epidermal growth factor and surfactant proteins during postnatal and compensatory lung growth. Am J Physiol Lung Cell Mol Physiol. 2002;283:L981-90.

22. Muratore CS, Nguyen HT, Ziegler MM, Wilson JM. Stretch-induced upregulation of VEGF gene expression in murine pulmonary culture: a role for angiogenesis in lung development. J Pediatr Surg. 2000;35:906-12.

23. Yew NS, Przybylska M, Ziegler RJ, Liu D, Cheng SH. High and sustained transgene expression in vivo from plasmid vectors containing a hybrid ubiquitin promoter. Mol Ther. 2001;4:75-82. 